\title{
Production Enhancement of Human Adipose- Derived Mesenchymal Stem Cells By Low-Intensity Ultrasound Stimulation
}

\section{Soohong Min ( $\nabla$ tnghd337@jejunu.ac.kr)}

Jeju National University https://orcid.org/0000-0002-2969-2640

\section{Yungsun Byeon}

EHL Bio Inc

\section{Min Kim}

EHL Bio Inc

\section{Youngjun Lee}

EHL Bio Inc

\section{Hongki Lee}

EHL Bio Inc

\section{Dong-Guk Paeng}

Jeju National University https://orcid.org/0000-0001-5106-3747

\section{Research Article}

Keywords: Human adipose-derived mesenchymal stem cells (hAdMSCs), Low-intensity ultrasound (LIUS) stimulation, Proliferation rate, Bromodeoxyuridine (BrdU) incorporation assay, Cell culture

Posted Date: November 19th, 2021

DOI: https://doi.org/10.21203/rs.3.rs-1069688/v1

License: (9) This work is licensed under a Creative Commons Attribution 4.0 International License. Read Full License 


\section{Abstract}

Background: Low-intensity ultrasound (LIUS) has been used to increase the proliferation rate of various stem cells including human adipose-derived mesenchymal stem cells (hAdMSCs). hAdMSCs is now commercially produced for various therapeutic applications. The purpose of this study was to show feasibility of enhancing the productivity of cell culture during 16-day cell culturing and increasing proliferation rate of hAdMSCs by LIUS stimulation with appropriate ultrasound parameters.

Methods: Beam patterns of 5 and $10 \mathrm{MHz}$ ultrasound transducers were measured to confirm the area of stimulation. The intensity of sound waves transmitted through a Petri-dish was measured in situ for quantitative evaluation. Bromodeoxyuridine (BrdU) incorporation assay was performed to search for appropriate parameters for LIUS stimulation of hAdMSCs. Cell culture medium supplemented with $8 \%$ fetal bovine serum (FBS) in a $35 \mathrm{~mm}$ Petri-dish was used for 16 days with subculture from 2 to 6 passage.

Results: A frequency of $5 \mathrm{MHz}$, an intensity of 300 , a duration of 10 minutes per day, and continuous waves with $100 \%$ duty cycle were the best parameters according to the BrdU assay of proliferation rate of hAdMSCs. LIUS stimulation group had about 3.25-fold greater number of cells from passage 2 to 6 compared with the control group. Doubling time was decreased to 4.44 hours in average. Cell viability was the same between the control and LIUS stimulation groups.

Conclusions: This study of enchanced proliferation rate and cell culture productivity of hAdMSCs by LIUS stimulation may lay the foundation for the application of LIUS stimulation in cell therapeutic industry by reducing the production cost and time required for cell therapy.

\section{Background}

Mesenchymal stem cells (MSCs) are attracting researchers due to their ability to self-renew, differentiation to other lineages of cells, and infinite proliferation [1]. MSCs may differentiate into a variety of cell types, osteoblasts, chondrocytes, and adipocytes [2]. MSCs are derived from adult tissues. They are unlikely to mutate into cancer cells when transplanted. They are not associated with nonimmunological or non-ethical concerns [3-5]. Human adipose-derived mesenchymal stem cells (hAdMSCs) are especially favored over other types of MSCs because of their availability and diverse clinical applications. hAdMSCs are widely utilized in pre-clinical and clinical trials of various conditions ranging from relatively mild diseases (such as skin regeneration, atopic dermatitis, Crohn's disease, and arthritis) to severe and incurable diseases such as ischemic stroke and Alzheimer's disease [6-10]. Cell banking systems have already been developed in anticipation of large-scale production after the development of hAdMSCs therapeutics [11]. Because cells exhibit different proliferation rates, manufacturing conditions for therapeutic hAdMSCs require strict management, including human resources and production costs. Besides, the cell culture process starting from isolation to a desired number of cells usually takes more than 10 days. The short expiration date of therapeutics requires 
meticulous patient scheduling. Therefore, a technology that can secure a large number of cells within a set time is crucial.

Some methods have already been proposed to improve stem cell proliferation. In vitro studies have been conducted by changing biochemical factors such as supplementation of cell culture media $[12,13]$ and physical factors such as applying mechanical stimulus that mimics the cell micro-environment in vivo [14-16]. The biochemical method using cell culture media has been adopted widely to increase proliferation rate $[17,18]$. In addition to biochemical factors, physical factors such as low-intensity ultrasound (LIUS) have been introduced in recent studies [19-27]. Altered physical pressure of ultrasound can enhance cell proliferation via integrin [28-30]. Ultrasound stimulation of the cells during culture can save cell culture time, manpower, and production cost for the cell therapy industry.

Frequency, intensity, and duration are key factors for LIUS stimulation. Frequency is important in LIUS stimulation [31] considering the cell size with respect to a wavelength. Intensity is important to choose appropriately for efficient stimulation not to be damaged depending on each cell type. Duration of a pulse should be considered in terms of to control temporal average intensity. Continuous wave or pulsed wave of ultrasound may have produced the different results [21]. Sonication time per a day and the days of sonication should affect the cell proliferation. Therefore, all these factors should be tested for the best results.

LIUS stimulation and cell proliferation rates have been reported in several studies. One study demonstrated that LIUS stimulation at a frequency of $1 \mathrm{MHz}$, an intensity of 500 or $1500 \mathrm{~mW} / \mathrm{cm}^{2}$, and a duration of 10 minutes for 2 to 4 days can improve the proliferation rate of neural crest stem cells in ethynyldeoxyuridine (EdU) assay [19]. Another study reported that LIUS stimulation at a frequency of 1 $\mathrm{MHz}$ and an intensity of 100,200 , or $300 \mathrm{~mW} / \mathrm{cm}^{2}$ for $10 \mathrm{~min} /$ day over a 7-day period can increase levels of extracelluar matrix protein, type II collagen, and proteoglycan and survivability of human articular chondrocytes [20]. These results demonstrate that LIUS not only can increase proliferation rate, but also can stimulate extracellular matrix proteins. After AdMSCs from guinea pigs were stimulated with LIUS at a frequency of $40 \mathrm{kHz}$ and an intensity of $120 \sim 350 \mathrm{~mW} / \mathrm{cm}^{2}$, results of MTT(3-(4, 5-dimethyl-2thiazolyl)-2, 5-diphenyltetrazolium bromide) assay revealed that cells proliferated better when they were treated continuously at an intensity of $230 \mathrm{~mW} / \mathrm{cm}^{2}$. However, the yield of cells cultured for many passages was not confirmed [21]. When dental pulp stem cells (DPSCs), bone marrow stem cells (BMSCs), and periodontal ligament stem cells (PDLSC) were stimulated with LIUS at a frequency of 1 $\mathrm{MHz}$, an intensity of 250 to $750 \mathrm{~mW} / \mathrm{cm}^{2}$, and a duration of 5 to 20 minutes, Bromodeoxyuridine (BrdU) incorporation assay revealed that DPSCs exhibited the highest proliferation rate at an intensity of 750 $\mathrm{mW} / \mathrm{cm}^{2}$, BMSCs showed the maximum proliferation at an intensity of $750 \mathrm{~mW} / \mathrm{cm}^{2}$ with 5 minutes of stimulation, and PDLSCs showed the maxium proliferatnion at an intensity of $250 \mathrm{~mW} / \mathrm{cm}^{2}$ with 5 minutes of stimulation [22]. All these results suggest that different types of stem cells might need different parameters of LIUS stimulation. In addition, although an improvement in the proliferation rate was confirmed in previous studies, these results are relative values, and it is difficult to predict how much production will increase during long-term culture. 
In various studies, cells subjected to LIUS stimulation showed either increased proliferation or survival rates under certain conditions. However, it is difficult to determine the appropriate conditions of various cell types for LIUS stimulation. Experimental conditions can vary even with the same cell type. Thus, applications of LIUS stimulation to cell therapy require accurate and quantitative ultrasound measurements with various parameters such as the frequency suitable for each cell size, the effective intensity without inflicting damage, the stimulation time, and the mode of ultrasound radiation. Ultrasound intensity applied to different cells should be adjusted according to the material and thickness of cell culture flask. The beam pattern in a non-uniform near-field of the ultrasound transducer also needs to be measured for LIUS stimulation conditions. The purpose of this study was to show feasibility of improving the productivity of cell culture during 16-day cell culturing and increasing proliferation rate of hAdMSCs by LIUS stimulation with accurately measured ultrasound field. This study may lay the foundation for the application of LIUS stimulation in cell therapeutic industry by reduction of the production cost and time required for cell therapy.

\section{Methods \& Experiments}

\section{BrdU incorporation assay}

BrdU incorporation assay was used to search appropriate parameters for LIUS stimulation of hAdMSCs. Fig. 1 shows the process of the BrdU incorporation assay. Cell proliferation ELISA(Enzyme-linked immunosorbent assay) and BrdU kit (Roche Applied Science, Germany) were used, which showed that the absorbance varied with labelling time. Therefore, it was necessary to establish a linear interval representing the absorbance proportional to the labelling time and the number of cells. After determining the linear interval, the BrdU incorporation assay was performed with cell densigy of 1200 cells/well using a labeling time of 16 hours. Each assay was performed using a single control. There were five experimental groups ( 4 wells were for each group) within the area of a LIUS transducer. The average absorbance was calculated from values of four wells. LIUS stimulation parameters were frequency, intensity, duration, and duty cycle. All experiments were conducted more than three times. Absorbance values were determined 7 times every 10 minutes starting from time zero.

\section{Cell culture experiments}

To validate effects of LIUS stimulation, two sets of control and stimulation groups were cultured from passages 2 to 6 by recording the number of cells in each passage. Experimental procedures and LIUS stimulation environment are detailed in Figs. 2 (a) and 2 (b), respectively. Each group consisted of three $35 \mathrm{~mm}$ round Petri-dishes (SPL Life Sciences, South Korea) with 20,000 cells/dish seeded. Cells from three dishes were collected and counted after 4 days of incubation. When subculturing to next passage, the same number of cells (20,000 cells) were seeded into each dish. Cells were incubated with alpha MEM (Gibco ${ }^{\mathrm{TM}}$, USA) supplemented with $8 \%$ fetal bovine serum (FBS, Atlas, USA), antibiotic-antimycotic (Gibco ${ }^{T M}$, USA), hydrocortisone (HC) (Sigma Aldrich, USA), epidermal growth factor (EGF) (Cha Meditec, South Korea), and fibroblast growth factor (FGF) (Cha Meditec, South Korea). The medium was changed 
every 48 hours. After incubation, cells were washed with normal saline solution (CJ Healthcare, South Korea), treated with trypLE express solution (Gibco ${ }^{\mathrm{TM}}, \mathrm{USA}$ ), and incubated at $37^{\circ} \mathrm{C}$ for 10 minutes in a $5 \%$ $\mathrm{CO}_{2}$ incubator. Cells were harvested by centrifugation at speed of 1500 rotation per minute for 5 minutes.

The number of viable cells was then counted. To determine the effect of temperature generated on the surface of the transducer during ultrasonic stimulation, the temperature of the ultrasound gel was measured after LIUS stimulation.

\section{Cell counting}

Numbers of hAdMSCs in the control and LIUS-stimulated groups were compared using an automated cell counter (LUNA-II' ${ }^{\mathrm{T}}$, Logos biosystems, South Korea) equipped with an image processing technique. Cell counter settings were: dilution factor, 2; size gating, 10 25 mm; noise reduction, 5; live cell sensitivity, 5; roundness, $30 \%$; de-clustering level, medium; and focusing method, autofocus. To establish the accuracy of the cell counter, the same number of cells were seeded into seven different wells. The difference between hemocytometer and automated cell counter was less than $4 \%$. These results are summarized in Table 1. Each slide of an automated cell counter was counted four times without overlapping regions.

The average value was highly precise compared with that of hemocytometer. Table 1 lists four counts of each slide, the average value of four counts, standard deviation (SD), and counts using a hemocytometer. Although the automated cell counter showed a low precision, the average value was similar to that of the hemocytometer. The deviation between four counts may be attributed to the non-uniform sample spread when pipetted to a slide of an automated cell counter.

Table 1

Summary of seven repeated cell counting experiments. Each slide of an automated cell counter was counted four times without overlapping regions. The average value showed high precision comparable to that of hemocytometer. Four counts of each slide, the average value of 4 counts, standard deviation (SD), and counts from a hemocytometer were confirmed. Although each count using an automated cell counter has low precision, the average value is similar to that of the hemocytometer. The deviation between 4 counts may be attributed to the non-uniform sample spread on the slide of an automated cell counter.

\begin{tabular}{|llllllll|}
\hline $\mathbf{x} \mathbf{1 0} / \mathbf{m L}$ & Count $\mathbf{1}$ & Count 2 & Count $\mathbf{3}$ & Count 4 & Average & SD & $\begin{array}{l}\text { Hemo } \\
\text { cytometer }\end{array}$ \\
\hline Well 1 & 1.26 & 1.22 & 1.25 & 1.17 & 1.22 & 0.040 & 1.27 \\
\hline Well 2 & 1.36 & 1.29 & 1.31 & 1.30 & 1.31 & 0.031 & 1.31 \\
\hline Well 3 & 1.39 & 1.30 & 1.50 & 1.39 & 1.39 & 0.100 & 1.35 \\
\hline Well 4 & 1.25 & 1.06 & 1.35 & 1.47 & 1.28 & 0.173 & 1.26 \\
\hline Well 5 & 1.44 & 1.24 & 1.47 & 1.00 & 1.28 & 0.217 & 1.26 \\
\hline Well 6 & 1.13 & 1.08 & 1.39 & 1.33 & 1.23 & 0.150 & 1.24 \\
\hline Well 7 & 1.18 & 1.08 & 1.39 & 1.26 & 1.22 & 0.131 & 1.25 \\
\hline
\end{tabular}


One of the most essential components in cell culture studies exposed to LIUS stimulation is quantitative evaluation of the ultrasound field. In this study, LIUS transducers, with an element size of $2.54 \mathrm{~cm}$ had resonance frequencies of $5 \mathrm{MHz}$ (V307-SU, OLYMPUS, USA) and $10 \mathrm{MHz}$ (V322-SU, OLYMPUS, USA). A pulser-receiver (5900PR, Panametrics, USA) and a hydrophone (0.2 $\mathrm{mm}$ needle hydrophone, Precision acoustics, UK) were used in beam pattern measurement to establish the stimulation área and attenuation coefficient of ultrasound signal passing through a Petri dish. Settings of the pulser-receiver were: pulse repetition frequency of $100 \mathrm{~Hz}$; damping resistance of 50 ohms yielding $20 \mathrm{~dB}$, attenuation of $0 \mathrm{~dB}$ at an energy level of $12.5 \mu \mathrm{J}$, and the filter frequency of 10 to $20 \mathrm{MHz}$. In LIUS stimulation of hAdMSCs, a US module (Research model, MediFUS, South Korea) was adopted as a transmission unit to adjust frequency, intensity, and duty cycle. By quantifying the spatial average of the temporal average intensity depending on the module input voltage with a power meter (UPM-DT-10PA, Ohmic Instruments, USA), desired intensities at each frequency were obtained and used for LIUS stimulation. A $3 \mathrm{~mm}$ ultrasound gel layer (Sono Jelly, Care Pharm, South Korea) was used to avoid an air layer between the surface of a US transducer and a Petri dish and to prevent cell damage caused by the heat produced from the surface of the US transducer. Fig. 3 (a) illustrates settings of ultrasound measurement.

\section{Beam pattern}

Figure 3 (b) shows a cross-sectional view of $5 \mathrm{MHz}$ transducer with a defective área. Experiments were conducted assuming that a defective area less than $10 \%$ of entire area was negligible. Figure 3 (c) is a longitudinal view of beam pattern of $5 \mathrm{MHz}$ transducer. It was measured from $3 \mathrm{~mm}$ to $80 \mathrm{~mm}$ along the beam direction. The distance from the transducer surface to the cell was $3 \mathrm{~mm}$ for the ultrasound gel layer, $1 \mathrm{~mm}$ for the Petri-dish layer, and $1 \mathrm{~mm}$ for the hydrophone measuring point. Thus, the total distance was $5 \mathrm{~mm}$. The sound pressure was effectively transmitted at $5 \mathrm{~mm}$ along the x-axis. The beam pattern of the $10 \mathrm{MHz}$ transducer was also measured. There was no defective area. An even sound pressure field was confirmed. Thus, the area stimulated by LIUS was identified as approximately $52 \%$ of the area of the $35 \mathrm{~mm}$ Petri-dish.

\section{Transmission coefficient}

$$
\begin{aligned}
Z(\text { Acousticimpedance }) & =\rho * C(1) \\
k(\text { WaveEquationNumber }) & =\frac{\omega}{C}=\frac{2 \pi f}{C}(2)
\end{aligned}
$$

$\mathrm{T}$ (Transmission coefficient of sound intensity at 3 layers

$$
=\frac{4}{2+\left(\frac{z_{3}}{Z_{1}}+\frac{z_{1}}{Z_{3}}\right) \cos ^{2}\left(k_{2} d\right)+\left(\frac{z_{2}^{2}}{Z_{1} Z_{3}}+\frac{z_{1} z_{3}}{Z_{2}{ }^{2}}\right) \sin ^{2}\left(k_{2} d\right)}
$$




$$
I(\text { Intensity })=\frac{P^{2}}{2 Z}(4)
$$

Transmission loss and attenuation should be considered to establish the attenuation of sound waves radiating from the transducer to hAdMSCs. Equation (3) considers sound wave transmission through three layers, including the ultrasonic gel, the Petri-dish, and the cell culture medium. $Z$ is the acoustic impedance of each layer and the product of the medium density $(\rho)$ and speed of sound(c) as indicated in Equation 1. $k$ denotes the wave number, which is obtained by dividing angular frequency $(\omega)$ by speed of sound as shown in Equation 2. $Z_{1}, Z_{2}$, and $Z_{3}$ represent the impedance of ultrasonic gel, Petri-dish, and cell culture medium, respectively. The cell culture medium and the ultrasonic gel were regarded as water in this study. $\rho_{1}, \rho_{2}$, and $\rho_{3}$ are 1000,1500 , and $1000 \mathrm{~kg} / \mathrm{m}^{3}$, respectively. $c_{1}, c_{2}$, are $c_{3}$ are 1500,2257 , and $1500 \mathrm{~m} / \mathrm{s}$, repectively Substituting these values, $Z_{1,3}=1.5 \times 10^{6}$ Rayl and $Z_{2}=2.37 \times 10^{6}$ Rayl, were obtained. Based on the thickness of Petri-dish and the wave number provided, the theoretical acoustic intensity transmission coefficient was calculated to be 0.82 using Equation 3 [32]. Fig. 3 (d) displays that the ratio of the peak-to-peak sound pressure with and without the Petri-dish (1.2726 and 1.1039 Mpa, respectively) was 0.867 . Based on the Equation 4 suggesting that the acoustic intensity was proportional to the pressure squared, the intensity transmission coefficient was 0.75 . Compared with the theoretical value of 0.82 , the acoustic intensity transmission coefficient was 0.07 less than the 3 -layer transmission coefficeint. The error may be attributed to the difference of acoustic impedance of ultrasonic gel and near-field inferference of sound. Accordingly, to stimulate cells at about $300 \mathrm{~mW} / \mathrm{cm}^{2}, 400 \mathrm{~mW} / \mathrm{cm}^{2}$ of an actual emission of sound wave was required.

\section{Statistical analysis}

All statistical analyses were performed using the MATLAB software Version 2019a (MathWorks Corp., USA). Statistical values were expressed as mean, SD, and t-test values. The correlation analysis between groups was performed using the ttest2 function in MATLAB software. The ttest2 function tests the null hypothesis that two data samples are derived from populations with the same mean. The significance level was set to be $p<0.05$ for all cases.

\section{Results}

In this study, LIUS stimulation was adopted to enhance the proliferation rate of hAdMSCs. Before stimulation, it is crucial to set suitable parameters and measure the ultrasound beam field quantitatively. To identify suitable parameters from a range of stimulation parameters, BrdU incorporation assay was performed with experiments repeated in a relatively short time. Appropriate conditions with the maximum stability and the highest proliferation rate of hAdMSCs under LIUS stimulation were: frequency of $5 \mathrm{MHz}$, intensity of $300 \mathrm{~mW} / \mathrm{cm}^{2}$, continuous wave, and duration of $10 \mathrm{~min} /$ day. In the cell culture experiment, using the selected parameters for LIUS stimulation, hAdMSCs were cultured from passages 2 to 6 . Culture studies were performed to compare the number of cells and doubling time between control and stimulation groups. 


\section{Cell proliferation rates with different ultrasound parameters}

BrdU incorporation assay was conducted to determine effects of LIUS stimulation parameters on cell proliferation rate. Absorbance values were determined up to 90 minutes. However, results were evaluated for 60 minutes before the absorbance was saturated. In Figs. 4 (a), 4 (b), 4 (c), and 4 (d), parameters were set to identify the most appropriate conditions. All experimental results were normalized against the absorbance of the control group after 60 minutes of fluorescence reaction. As shown in Fig. 4 (a), at a frequency of $10 \mathrm{MHz}$, the normalized absorbance was 1.76, which was the largest compared with the control. At frequencies of $5 \mathrm{MHz}, 4 \mathrm{MHz}, 6 \mathrm{MHz}$, and $9 \mathrm{MHz}$, normalized absorbance values were 1.32, $1.19,1.07$, and 0.8 , respectively. Although the absorbance at the frequency of $10 \mathrm{MHz}$ was the highest, 5 $\mathrm{MHz}$ with a standard deviation of 0.23 was selected because the standard deviation at $10 \mathrm{MHz}$ was relatively high at 0.47 . As shown in Fig. 4 (a), the absorbance at $9 \mathrm{MHz}$ was 0.8 due to the heat generated systemically on the transducer surface at an intensity of $300 \mathrm{~mW} / \mathrm{cm}^{2}$. Fig. 4 (b) shows the proliferation rate acording to the intensity of the ultrasound signal. As shown in the graph, at $300 \mathrm{~mW} / \mathrm{cm}^{2}$, the absorbance was the highest (1.40), whereas the absorbance value was 1.35 at $500 \mathrm{~mW} / \mathrm{cm}^{2}$ and 1.17 at $100 \mathrm{~mW} / \mathrm{cm}^{2}$. Absorbance values at higher intensities $\left(700 \mathrm{~mW} / \mathrm{cm}^{2}\right.$ and $\left.900 \mathrm{~mW} / \mathrm{cm}^{2}\right)$ were lower than that of control because of the heat generated on the surface of the transducer, which affected cells. The change in absorbance based on duty cycle (0 100\%) is described in Fig. 4 (c). No change in absorbance occurred from $20-60 \%$, although it increased to 1.31 at $80 \%$ and 1.51 at $100 \%$. Fig. 4 (d) displays values depending on the duration of stimulation time. Upon stimulation of cells for 10 minutes each day, the absorbance was the highest at 1.34. Stimulation twice or three times daily for 10 minutes resulted in absorbance of 1.25 and 1.23 , respectively, suggesting that the proliferation rate decreased as the stimulation time increased to 20 and 30 minutes. Table 2 summarizes all absorbance values and SDs of all experimented parameters. 
Table 2

Average of normalized absorbance values and standard deviation (SD) based on BrdU incoporation assay.

\begin{tabular}{|llllllll|}
\hline $\begin{array}{l}\text { Frequency } \\
\text { (MHz) }\end{array}$ & Control & $\mathbf{4}$ & $\mathbf{5}$ & $\mathbf{6}$ & $\mathbf{9}$ & 10 \\
\hline Normalized Absorbance & 1.00 & 1.19 & 1.32 & 1.04 & 0.80 & 1.76 \\
\hline SD & 0.12 & 0.22 & 0.23 & 0.21 & 0.18 & 0.47 \\
\hline Intensity & Control & 100 & 300 & 500 & 700 & 900 \\
$\left(m W / \mathrm{cm}^{2}\right)$ & & & & & & \\
\hline Normalized Absorbance & 1.00 & 1.17 & 1.40 & 1.35 & 0.98 & 0.94 \\
\hline SD & 0.28 & 0.19 & 0.22 & 0.18 & 0.15 & 0.18 \\
\hline Duty cycle & Control & 20 & 40 & 60 & 80 & Continuous wave \\
(\%, period = 10 ms) & & & & & & \\
\hline Normalized Absorbance & 1.00 & 1.21 & 1.17 & 1.15 & 1.31 & 1.51 \\
\hline SD & 0.11 & 0.06 & 0.14 & 0.27 & 0.23 & 0.15 \\
\hline Stimulation time & Control & 10 & 20 & 30 & $10 \times 2$ & $10 \times 3$ \\
\hline (Min) & & & & & & \\
\hline Normalized Absorbance & 1.00 & 1.34 & 1.17 & 1.03 & 1.25 & 1.23 \\
\hline SD & 0.15 & 0.20 & 0.15 & 0.12 & 0.10 & 0.18 \\
\hline
\end{tabular}

\section{Increased number of cells during 16-day culturing}

A long-term subculturing experiment was conducted with set parameters of LIUS stimulation based on results of BrdU incorporation assay. Cell numbers in stimulated groups of passage 3 shown in Fig. 5 were higher than those in control groups. Results revealed that the number of cells in control groups ( $\mathrm{C} 1$ and C2) at passage 3 was increased 5.28-fold on average compared to the seeding number of cells. In passages 4,5 , and 6 , the average number of cells increased 10.34-, 10.51-, and 7.48- fold, respectively. In case of ultrasound-stimulated groups ( $\mathrm{U} 1$ and $\mathrm{U} 2$ ), the average number of cells compared with seeding number of cells was increased 8.35-, 12.20-, 13.35-, and 10.07-fold in passages $3,4,5$, and 6, respectively. The decreased cell proliferation rate in passage 6 was attributed to characteristics of cells. If the seeding number was not restricted to 2170 cells $/ \mathrm{cm}^{2}$ and all cells were seeded by increasing the number of Petridishes instead, the total number of cells would have increased about 4291-fold from passages 2 to 6 in the control group and about 13982-fold in the stimulated group (3.25-fold higher than that in the control group). A summary of the number of cells after culture compared with the number of seeding cells is presented in Table 3. 
Table 3

Results of cell culture experiment.

\begin{tabular}{|llllll|}
\hline & Seeding cells & Passage 3 & Passage 4 & Passage 5 & Passage 6 \\
\hline C1 $\left(\times 10^{6}\right)$ & 0.060 & 0.303 & 0.638 & 0.618 & 0.437 \\
\hline C2 $\left(\times 10^{6}\right)$ & 0.060 & 0.330 & 0.603 & 0.643 & 0.460 \\
\hline Average $\left(\times 10^{6}\right)$ & 0.060 & 0.317 & 0.621 & 0.631 & 0.448 \\
\hline Multiples of seeding cells & 1.00 & 5.28 & 10.34 & 10.51 & 7.48 \\
\hline U1 $\left(x 10^{6}\right)$ & 0.060 & 0.507 & 0.732 & 0.848 & 0.618 \\
\hline U2 $\left(x 10^{6}\right)$ & 0.060 & 0.451 & 0.732 & 0.787 & 0.590 \\
\hline Average $\left(x 10^{6}\right)$ & 0.060 & 0.501 & 0.732 & 0.818 & 0.604 \\
\hline Multiples of seeding cells & 1.00 & 8.35 & 12.20 & 13.63 & 10.07 \\
\hline
\end{tabular}

\section{Doubling time}

Cumulative population doubling level (CPDL) and doubling time were calculated based on the subculture cycle and number of cells in a given subculture. In Fig. 6 (a), the CPDL of the control group increased from 2.32 to 12.15 , while the CPDL of stimulated group increased more steeply from 2.91 to 13.87. Fig. 6 (b) explains the decrease in average doubling time from passage 3 to passage 6 between the control and stimulated groups. The control group had an average doubling time of 32.63 hours, while the stimulated group showed 28.19 hours, which was 4.44 hours less on average. Using t-test to determine the statistical similarity between the two groups, the null hypothesis was rejected at the significance level of $5 \%$ with a p-value of 0.0485 . Analysing the data from Fig. 6 (c), the difference in doubling time between the two groups in passage 2 was the highest, ranging from 6 to 10 hours, and that in passage 3 was the lowest at 1.5 to 2.7 hours. As the doubling time increased from passage 3 to passage 5 , the efficiency of the LIUS stimulation also increased. These results suggest that LIUS stimulation might have a greater effect in reducing the incubation time of subculture to passage with a shorter doubling time.

\section{Cell characteristics and viability}

To determine characteristics and survival rates of hAdMSCs upon stimulation with LIUS, fluorescenceacticated cell sorting (FACS; Z6511540132, BD, USA) and an automated cell counter were employed. Table 4 presents FACS data based on purity markers (CD34, CD45) and identity markers (CD73, CD95, and CD105) for both control and stimulated groups, establishing their identities as stem cells. As a result of the purity test, no significant difference was found between control and LIUS groups, with event incidence rate of less than $1 \%$. There was no signficiant difference between control and LIUS stimulation groups either based on results of the identification test, with a maximum of $0.49 \%$. These results showed no difference in cell characteristics between the control and LIUS stimulated groups. Table 5 lists survival 
rates from automated cell counter which showed survival of more than $95 \%$ in both groups, demonstrating the lack of adverse effects of LIUS stimulation.

Table 4

Results of purity and identity tests of cells from passage 6. CD34 and CD45 markers were used for stem cell purity test. CD73, CD95, and CD105 markers were used for stem cell identification test. Results showed no significant difference between the control and LIUS-stimulated groups.

\begin{tabular}{|llllll|}
\hline \multirow{2}{*}{ (10000 events) } & \multicolumn{2}{l}{ Purity Test } & \multicolumn{3}{l|}{ Identification Test } \\
\cline { 2 - 6 } & CD34 & CD45 & CD73 & CD95 & CD105 \\
\hline C1 & 0.36 & 1.20 & 99.02 & 98.99 & 99.04 \\
\hline C2 & 0.32 & 0.53 & 99.40 & 98.97 & 99.34 \\
\hline U1 & 0.32 & 1.09 & 99.18 & 98.93 & 99.06 \\
\hline U2 & 0.44 & 1.03 & 99.51 & 98.67 & 99.05 \\
\hline
\end{tabular}

Table 5

Cell viability of control groups $(\mathrm{C} 1, \mathrm{C} 2)$ and LIUS stimulation groups $(\mathbf{U} 1, \mathbf{U} 2)$. Cell viability in each passage exceeded 95\%, confirming that LIUS stimulation did not decrease cell viability.

\begin{tabular}{|lllll|}
\hline \% & Passage 3 & Passage 4 & Passage 5 & Passage 6 \\
\hline C1 & 98.10 & 97.50 & 98.70 & 98.50 \\
C2 & 98.38 & 98.12 & 98.13 & 98.05 \\
U1 & 95.43 & 99.03 & 98.28 & 98.63 \\
U2 & 97.98 & 98.60 & 98.73 & 97.55 \\
\hline
\end{tabular}

\section{Discussion}

In this study, LIUS stimulation, one of various mechanical stimulation methods, was used to improve the proliferation rate of hAdMSCs. BrdU incorporation assay was repeatedly performed to determine appropriate ultrasound parameters for cell stimulation. As a result, a frequency of $5 \mathrm{MHz}$, an intensity of $300 \mathrm{~mW} / \mathrm{cm}^{2}$, a duration of $10 \mathrm{~min} /$ day, and continuous wave were selected as the optimal conditions within the scope of this study. In this study, the stimulation area and the effectiveness of the ultrasound transducer were quantitatively evaluated by measuring the beam pattern. The degree of attenuation of ultrasound transmitted through the Petri-dish was also experimentally confirmed. With set parameters, hAdMSCs were cultured from passage 2 to passage 6 for 16 days. Results demonstrate that LIUS stimulation increased the cell population by 3.25 -fold compared with the control group. LIUS stimulation also reduced an average of 4.44 hours of doubling time in 4 passages. The results confirmed that the effect of the LIUS stimulation on the reduction of doulbing time was greater as the doulbing time was 
longer. Application of low-intensity ultrasound to hAdMSCs culture not only induced an increase in cell proliferation rate, but also preserved characteristics of stem cells. Cell viability in each passage exceeded $95 \%$, indicating that the LIUS stimulation did not cause any harm. These results suggest that the cell culture time can be shortened by about 3 days for 16 days. This is crucial in the cell therapeutics industry, which requires tight patient scheduling due to short expiration date of the product and lengthy production requiring human resources and expenses.

\section{Ultrasound system and parameters}

The generation of the same intensity of $300 \mathrm{~mW} / \mathrm{cm}^{2}$ from several frequencies using two transdcuers with diferent frequency responses requires adjustment of input voltages. For frequencies outside the resonance frequency of each transducer ( 4 and $6 \mathrm{MHz}, 9 \mathrm{MHz}$ ) requiring increased amount of voltage, heat is easily generated not only on the electrical system, but also on the surface of the ultrasound transducer. Continuous wave generates higher heat compared with pulsed wave, contributing to similar or lower proliferation rate compared to the control rate at frequencies of 6 and $9 \mathrm{MHz}$ and at intensities of 700 and $900 \mathrm{~mW} / \mathrm{cm}^{2}$ as shown in Figs. 4 (a) and 4 (b). Temperatures measured under those conditions were $38.5,42,42$, and $45^{\circ} \mathrm{C}$, which were substantially higher than the incubation temperature of $37^{\circ} \mathrm{C}$, and in other conditions. Resolution of these complexities requires manufacture of an ultrasound transducer and systemic supplementation by matching impedance of electronic module, or installation of insulator between the transducer and the Petri-dish.

The frequency of $5 \mathrm{MHz}$ was selected due to the relatively higher stability and constancy. Proliferation rate at $10 \mathrm{MHz}$ was the highest. However, its variation was high. With the optimized electornic system, the higher frequencies including the resonant frequency similar to cell size and cell layer need to be further investigated in future. Cellular substrate of hAdMSC increased from 10 30 $\mu \mathrm{m}$ to about $100 \mu \mathrm{m}$. Considering that the wavelength of $5 \mathrm{MHz}$ was $300 \mu \mathrm{m}$, the LIUS stimulation efficiency was increased at shorter wavelength or higher freqeuncy.

Continuous wave had the highest proliferation rate as shown in Fig. 4 (c), but cells showed higher rate when they were treated for 10 minutes each day compared with longer duration, thereby establishing that the proliferation efficiency did not increase proportionate to the exposure time. However, the reasons for higher proliferation rate at 10 minutes each day need to be explored to establish the optimal diurnal duration. Continuous wave at higher intensity generates heat in the elelctronic system and transducer easily, suggesting the need for selecting the right intensity with appropriate sonication duration for optimal conditions without heat generation.

\section{Limitation}

Cell characteristics including proliferation rate might differ between individual cases. However, this study was perfomed with an assumption that the allogenic line of hAdMSCs would share optimal parameter of LIUS stimulation, although it might differ in the degree of increase in the proliferation rate according to 
each LIUS stimulation parameter. Therefore, a single line of hAdMSCs was used for all BrdU incorporation assays and another line of hAdMSCs was used for whole-cell culture experiment from passage 2 to 6 .

The diamater of the Petri-dish used in this study was $35 \mathrm{~mm}$, a little wider than the diameter of the transducer aperture, $31 \mathrm{~mm}$, with stimulating diameter being $25.4 \mathrm{~mm}$ as shown in Figs. 3 (b) and 3 (c). Thus, $52 \%$ of whole Petri-dish area was actually stimulated, suggesting that the proliferation rate might increase by using a transducer covering the whole surface area. Cells are usually cultured in $75,175 \mathrm{~mm}^{2}$ flasks, which are much wider than the Petri-dish used in this experiment. Therefore, industrial application of LIUS stimulation requires further investigations to determine the appropriate size of the transducer and the best area of stimulation.

\section{Conclusion}

LIUS stimulation with quantitative measurement was adopted in this study to enhance the proliferation rate of hAdMSCs. Appropriate parameters of LIUS stimulation in this study were validated via repeated BrdU incorporation assays. Incubation of hAdMSCs from passages 2 to 6 using set parameters of LIUS stimulation revealed that the average number of cells and the average doubling time of stimulated groups were 3.25-fold higher and 4.44 hours shorter than those in the control groups, respectively, without damaging cells. These results can be applied to cell therapeutics industry to reduce cell culture time and cost of manufacture.

\section{Abbreviations}

hAdMSCs: Human adipose-derived mesenchymal stem cells; LIUS: Low-intensity ultrasound; BrdU: Bromodeoxyuridine; FBS: Fetal bovine serum; MSCs: Mesenchymal stem cells; EdU: ethynyldeoxyuridine; DPSC: Dental pulp stem cells; BMSC: Bone marrow stem cells; PDLSC: Periodontal ligament stem cells; POD: Peroxidase; ELISA: Enzyme-linked immunosorbent assay; HC: Hydrocortisone; EGF: Epidermal growth factor; FGF: Fibroblast growth factor; SD: Standard deviation; CPDL: Cumulative population doubling level.

\section{Declarations}

\section{Ethics approval and consent to participate}

Written consent was obtained from all participant. The study protocol was approved by the Institutional Review Board of Jeju National University (approval number: 2020-061-001).

\section{Consent for publication}

Not applicable 


\section{Availability of data and materials}

The datasets used and/or analysed during the current study are available from the corresponding author upon reasonable request.

\section{Competing interests}

The authors have no conflict of interest to declare.

\section{Funding}

This work was supported by a grant (2018R1A2B2007997) of the National Research Foundation (NRF) funded by the Korea government (MSIT). This study was also supported by a grant (2019R1A6A1A10072987) of the Basic Science Research Program at the Research Institute for Basic Sciences (RIBS) of Jeju National University through the NRF funded by the Ministry of Education, Republic of Korea.

\section{Authors' contributions}

SM performed validation experiment and analysed the data. SM was a major contributor to the writing of the manuscript. YB cultured hAdMSCs and performed LIUS stimulation. MK performed cell characterization. YL provided advice and methods for overall study and writing of the paper. HL provided the overall direction of research in the field of biology and reviewed the paper. DP provided the overall direction of research in the field of ultrasound and reviewed the paper. All authors have read and approved the manuscript.

\section{Acknowledgements}

The following manuscript was proofread and edited by the professional English editors at HARRISCO.

\section{References}

1. Pittenger MF, Discher DE, Péault BM, et al. Mesenchymal stem cell perspective: cell biology to clinical progress. NPJ Regenerative medicine 2019;4(1):1-15.

2. Zakrzewski W, Dobrzyński M, Szymonowicz M, et al. Stem cells: past, present, and future. Stem cell research \& therapy 2019;10(1):1-22.

3. Caplan Al, Bruder SP. Mesenchymal stem cells: building blocks for molecular medicine in the $21 \mathrm{st}$ century. Trends in molecular medicine 2001;7(6):259-264. 
4. Caplan Al. Mesenchymal stem cells. Journal of orthopaedic research 1991;9(5):641-650.

5. Wang X, Lin Q, Zhang T, et al. Low-intensity pulsed ultrasound promotes chondrogenesis of mesenchymal stem cells via regulation of autophagy. Stem cell research \& therapy 2019;10(1):1-11.

6. Charles-de-Sá L, Gontijo-de-Amorim NF, Takiya CM, et al. Antiaging treatment of the facial skin by fat graft and adipose-derived stem cells. Plastic and reconstructive surgery 2015;135(4):999-1009.

7. Vu Q, Xie K, Eckert M, et al. Meta-analysis of preclinical studies of mesenchymal stromal cells for ischemic stroke. Neurology 2014;82(14):1277-1286.

8. Álvaro-Gracia JM, Jover JA, García-Vicuña R, et al. Intravenous administration of expanded allogeneic adipose-derived mesenchymal stem cells in refractory rheumatoid arthritis (Cx611): results of a multicentre, dose escalation, randomised, single-blind, placebo-controlled phase lb/lla clinical trial. Annals of the rheumatic diseases 2017;76(1):196-202.

9. Panés J, García-Olmo D, Van Assche G, et al. Expanded allogeneic adipose-derived mesenchymal stem cells (Cx601) for complex perianal fistulas in Crohn's disease: a phase 3 randomised, doubleblind controlled trial. The Lancet 2016;388(10051):1281-1290.

10. Nasb M, Liangjiang $H$, Gong $C$, et al. Human adipose-derived Mesenchymal stem cells, low-intensity pulsed ultrasound, or their combination for the treatment of knee osteoarthritis: study protocol for a first-in-man randomized controlled trial. BMC musculoskeletal disorders 2020;21(1):1-8.

11. De Rosa A, De Francesco F, Tirino V, et al. A new method for cryopreserving adipose-derived stem cells: an attractive and suitable large-scale and long-term cell banking technology. Tissue Engineering Part C: Methods 2009;15(4):659-667.

12. Worster AA, Brower-Toland BD, Fortier LA, et al. Chondrocytic differentiation of mesenchymal stem cells sequentially exposed to transforming growth factor- $\beta 1$ in monolayer and insulin-like growth factor-I in a three-dimensional matrix. Journal of Orthopaedic Research 2001;19(4): 738-749.

13. Hanada K, Dennis JE, Caplan Al. Stimulatory effects of basic fibroblast growth factor and bone morphogenetic protein-2 on osteogenic differentiation of rat bone marrow-derived mesenchymal stem cells. Journal of Bone and Mineral Research 1997;12(10):1606-1614.

14. Li K, Ning T, Wang H, et al. Nanosecond pulsed electric fields enhance mesenchymal stem cells differentiation via DNMT1-regulated OCT4/NANOG gene expression. Stem cell research \& therapy 2020;11(1):1-14.

15. Luu YK, Capilla E, Rosen CJ, et al. Mechanical stimulation of mesenchymal stem cell proliferation and differentiation promotes osteogenesis while preventing dietary-induced obesity. Journal of Bone and Mineral Research 2009;24(1):50-61.

16. McMahon LA, Reid AJ, Campbell VA, et al. Regulatory effects of mechanical strain on the chondrogenic differentiation of MSCs in a collagen-GAG scaffold: experimental and computational analysis. Annals of biomedical engineering 2008;36(2):185-194.

17. Gharibi B, Hughes FJ. Effects of medium supplements on proliferation, differentiation potential, and in vitro expansion of mesenchymal stem cells. Stem cells translational medicine 2012;1(11):771782. 
18. Chase LG, Lakshmipathy U, Solchaga LA, et al. A novel serum-free medium for the expansion of human mesenchymal stem cells. Stem cell research \& therapy 2010;1(1):1-11.

19. Lv Y, Zhao P, Chen G, et al. Effects of low-intensity pulsed ultrasound on cell viability, proliferation and neural differentiation of induced pluripotent stem cells-derived neural crest stem cells. Biotechnology letters 2013;35(12):2201-2212.

20. Choi BH, Woo Jl, Min BH, et al. Low-intensity ultrasound stimulates the viability and matrix gene expression of human articular chondrocytes in alginate bead culture. Journal of Biomedical Materials Research Part A 2006;79(4):858-864.

21. Hormozi-Moghaddam Z, Mokhtari-Dizaji M, Nilforoshzadeh MA, et al. Low-intensity ultrasound to induce proliferation and collagen I expression of adipose-derived mesenchymal stem cells and fibroblast cells in co-culture. Measurement 2021;167:108280.

22. Gao Q, Walmsley AD, Cooper PR, et al. Ultrasound stimulation of different dental stem cell populations: role of mitogen-activated protein kinase signaling. Journal of endodontics 2016;42(3):425-431.

23. Yang MH, Lim KT, Choung PH, et al. Application of ultrasound stimulation in bone tissue engineering. International journal of stem cells 2010;3(2):74.

24. Huang D, Gao Y, Wang S, et al. Impact of low-intensity pulsed ultrasound on transcription and metabolite compositions in proliferation and functionalization of human adipose-derived mesenchymal stromal cells. Scientific reports 2020;10(1):1-19.

25. Moghaddam ZH, Mokhtari-Dizaji M, Nilforoshzadeh MA, et al. Low-intensity ultrasound combined with allogenic adipose-derived mesenchymal stem cells (AdMSCs) in radiation-induced skin injury treatment. Scientific Reports 2020;10(1):1-19.

26. Choi $\mathrm{WH}$, Choi BH, Min BH, et al. Low-intensity ultrasound increased colony forming unit-fibroblasts of mesenchymal stem cells during primary culture. Tissue Engineering Part C: Methods 2011;17(5):517-526.

27. Zhou S, Schmelz A, Seufferlein T, et al. Molecular mechanisms of low intensity pulsed ultrasound in human skin fibroblasts. Journal of Biological Chemistry 2004;279(52):54463-54469.

28. Sato M, Nagata K, Kuroda S, et al. Low-intensity pulsed ultrasound activates integrin-mediated mechanotransduction pathway in synovial cells. Annals of biomedical engineering 2014;42(10):2156-2163.

29. Xia P, Wang X, Qu Y, Lin Q, et al. TGF- $\beta 1$-induced chondrogenesis of bone marrow mesenchymal stem cells is promoted by low-intensity pulsed ultrasound through the integrin-mTOR signaling pathway. Stem cell research \& therapy 2017;8(1):1-11.

30. Whitney NP, Lamb AC, Louw TM, et al. Integrin-mediated mechanotransduction pathway of lowintensity continuous ultrasound in human chondrocytes. Ultrasound in medicine \& biology 2012;38(10):1734-1743.

31. Schuster A, Schwab T, Bischof M, et al. Cell specific ultrasound effects are dose and frequency dependent. Annals of Anatomy-Anatomischer Anzeiger 2013;195(1):57-67. 
32. Mabuza RB, Netshidavhini N. The effect of a middle layer on ultrasonic wave propagating in a threelayer structure. The Journal of the Acoustical Society of America 2013;133(5):3447-3447.

\section{Figures}

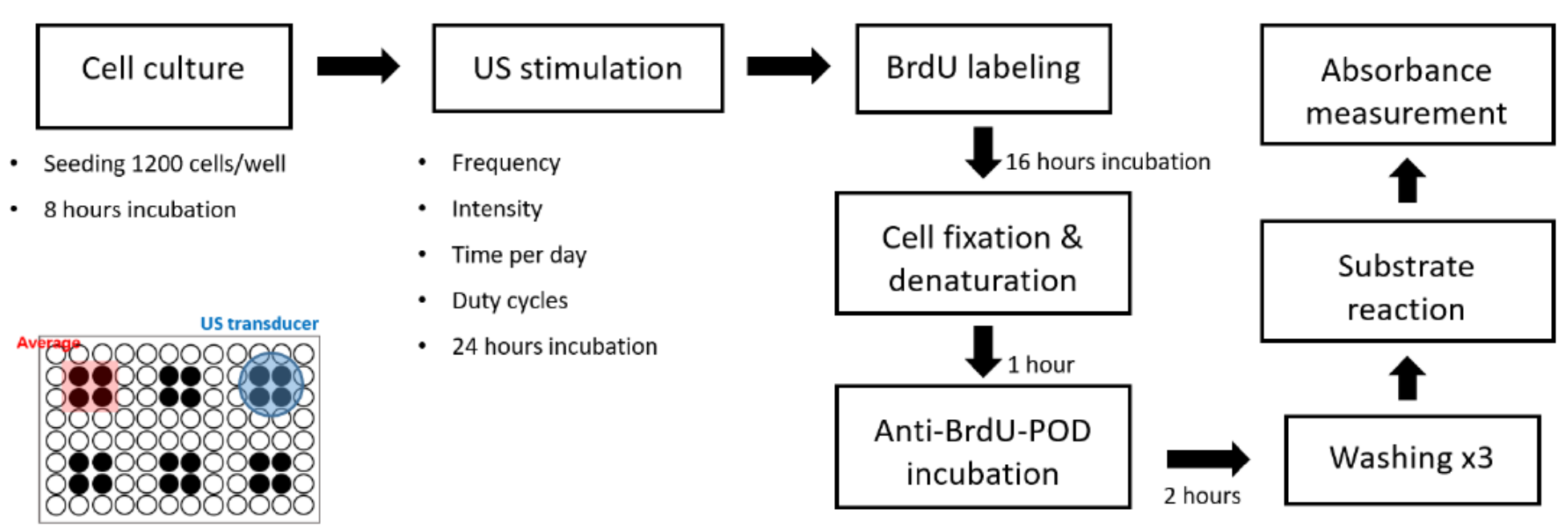

\section{Figure 1}

Block diagram outlining ultrasound stimulation and BrdU incorporation assay procedures. Cells were seeded at a density of 1200 cells/well. LIUS stimulation was applied after 8 hours of incubation. BrdU incorporation assay was conducted at 24 hours after LIUS stimulation to determine hAdMSC proliferation rates depending on various ultrasound parameters such as frequency, intensity, duty cycle, and sonication time per day. BrdU was incorporated into the newly synthesized DNA strand, replacing thymidine in the DNA of proliferating cells duringBrdU labelling for 16 hours. Anti-BrdU-PODs were added after cell fixation. Cells were washed three times. A substrate solution was added, followed by measurement of absorbance using ELISA. A 96-well plate used for the experiment is depicted on the lower left of the diagram. Experiments were conducted in four wells in each experimental group covering the area of the US trasducer. BrdU: Bromodeoxyuridine; LIUS: Low-intensity ultrasound; hAdMSC: Human adipose derived mesenchymal stem cell; POD: Peroxidase; ELISA: Enzyme-linked immunosorbent assay. 
a

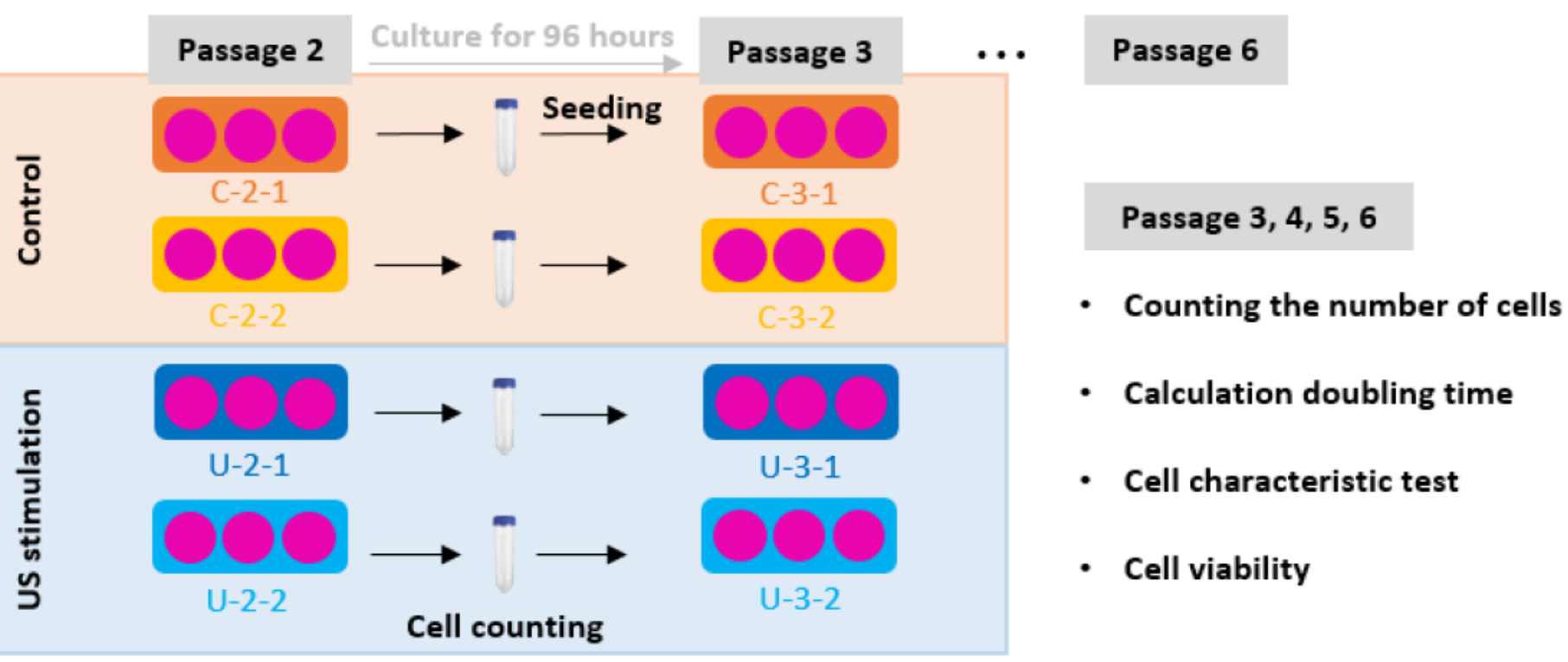

b

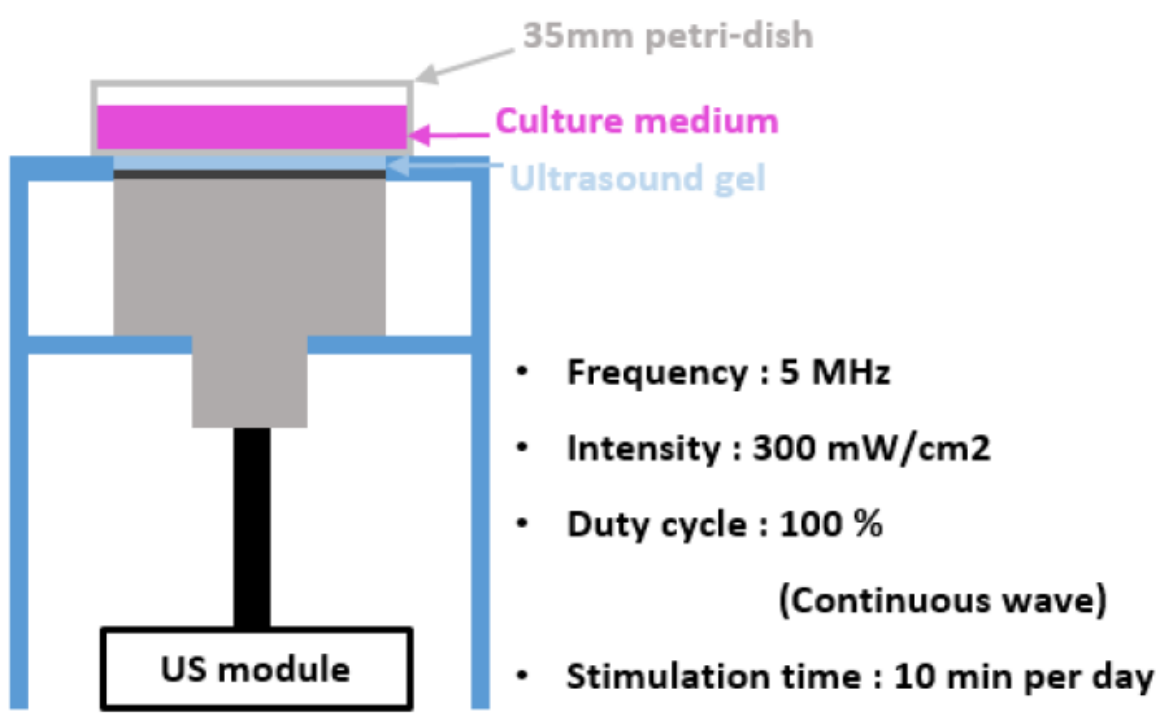

Figure 2

Cell culture experiments during 16-day. (a) Subculturing steps from passages 2 to 6 . Each passage was conducted after 96 hours of incubation. For each passage, the number of cells, doubling time, MSCs characteristics, and survival rates were recorded. (b) A diagram of LIUS stimulation environment used to stimulate hAdMSCs in cell culture experiments is shown. Cells were stimulated under appropriate ultrasound parameters within the scope of this study during the BrdU assay. MSCs: Mesenchymal stem cells; LIUS: Low-intensity ultrasound; hAdMSCs: Human adipose derived mesenchymal stem cells; BrdU: Bromodeoxyuridine. 


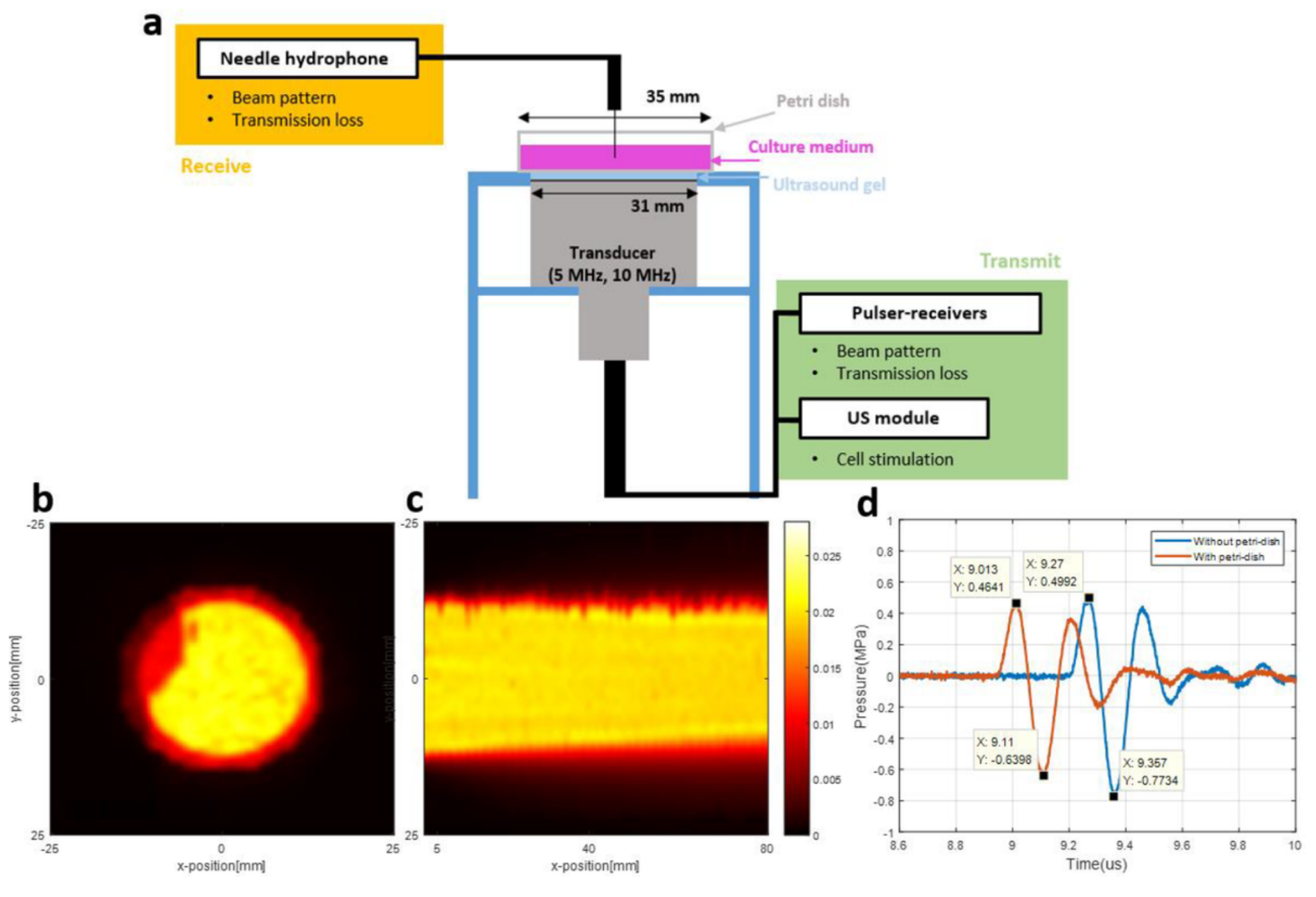

Figure 3

Settings of an ultrasound measurement system used to evaluate ultrasound conditions for stimulating hAdMSCs. (a) Illustration of the experimental system. Pulser-receiver (transmission unit) (5900PR, Panametrics, USA), hydrophone (reception unit) ( $0.2 \mathrm{~mm}$ needle hydrophone, Precision Acoustics, UK), and LIUS transducers with resonance frequencies of $5 \mathrm{MHz}$ (V307-SU, OLYMPUS, USA) and $10 \mathrm{MHz}$ (V322-SU, OLYMPUS, USA). (b) Beam pattern of $5 \mathrm{MHz}$ ultrasound transducer, cross-sectional view at 3 $\mathrm{mm}$ at (c). (c) Beam pattern of $5 \mathrm{MHz}$ ultrasound transducer, longitudinal view. (d) Ultrasound signal measured using the hydrophone with or without the Petri-dish. When the ultrasound signal passes through the Petri-dish, the sound speed is increased to receive the signal earlier while the peak-to-peak sound pressure is decreased. hAdMSCs: Human adipose derived mesenchymal stem cells; LIUS: Lowintensity ultrasound. 
a

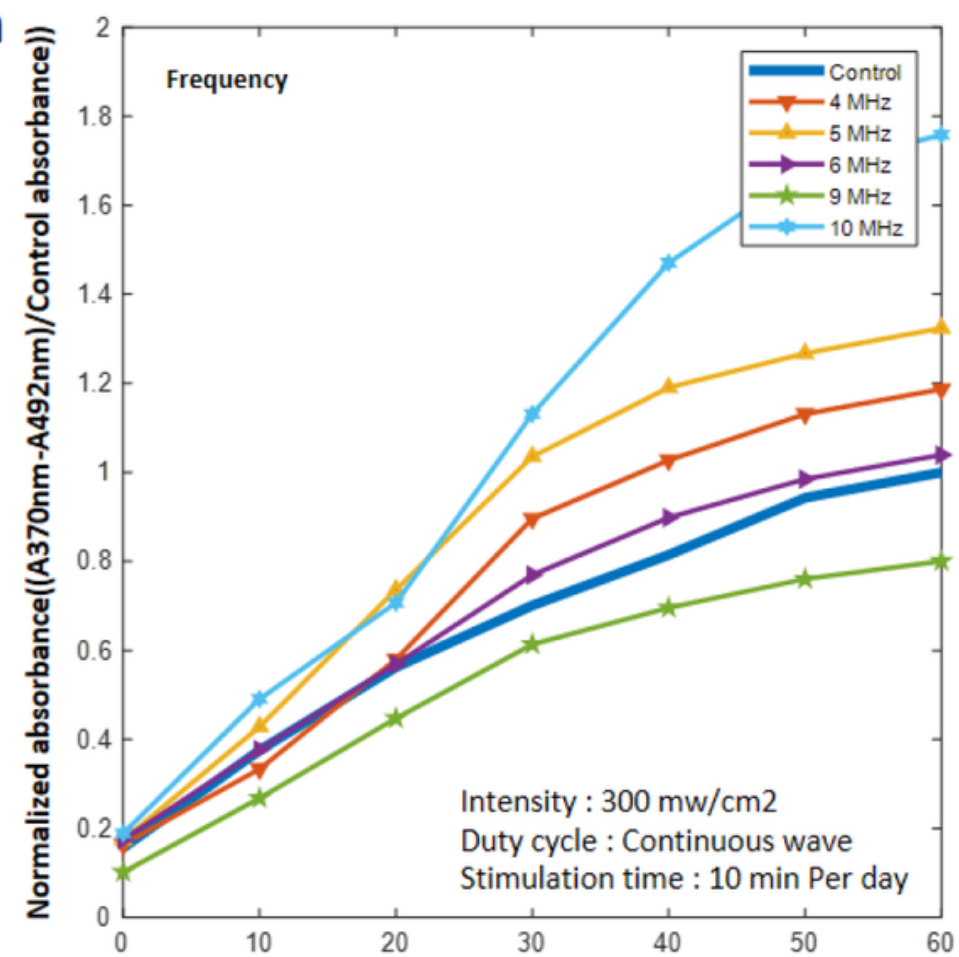

C

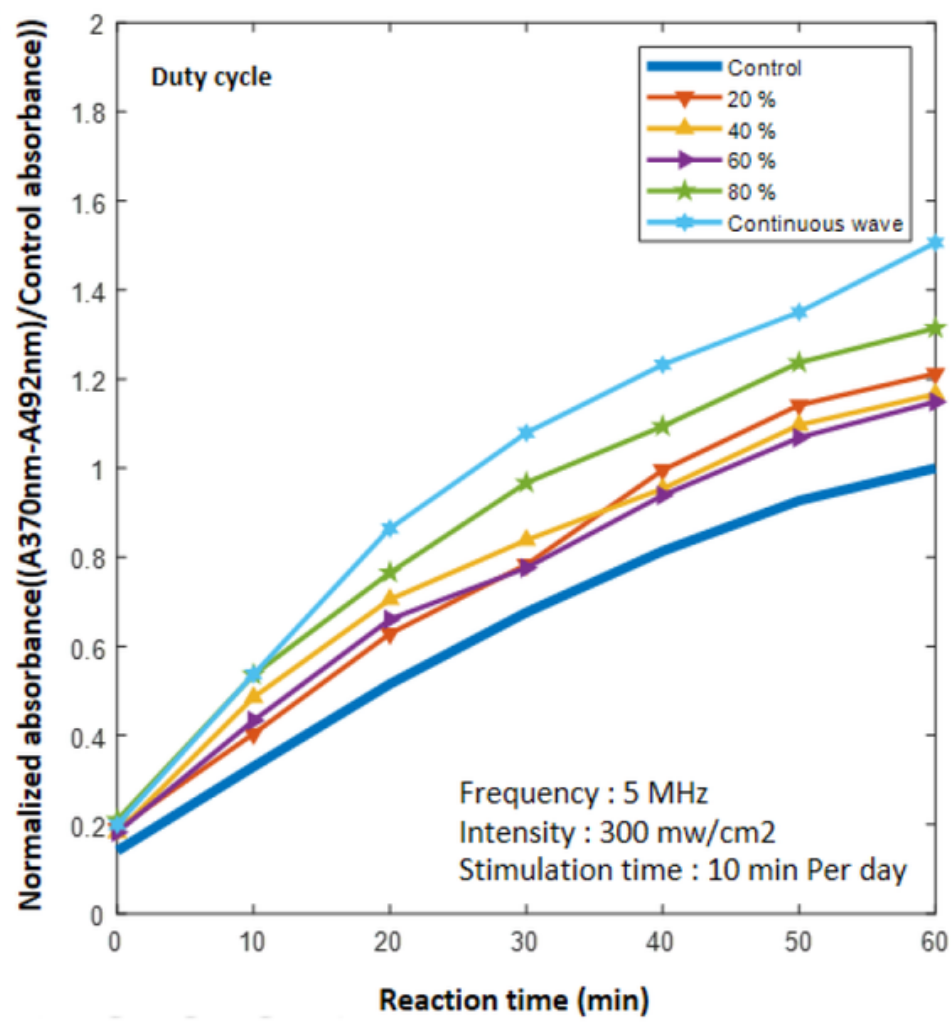

b

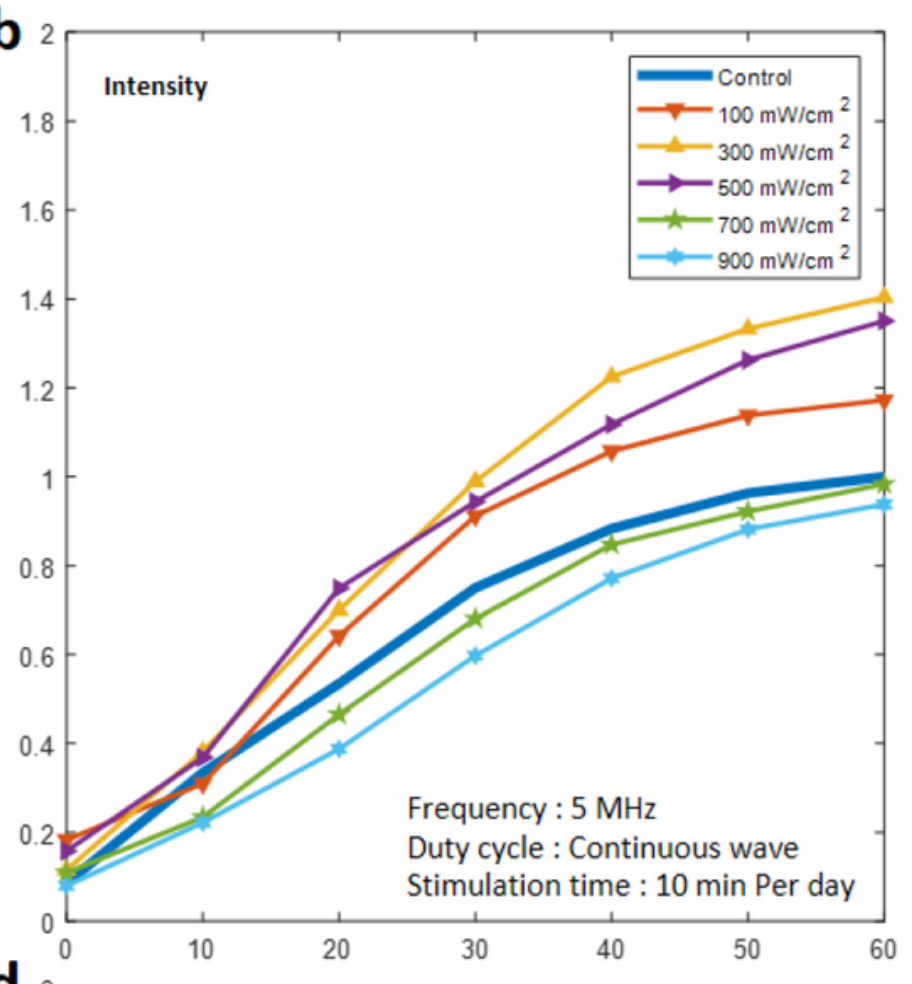

d

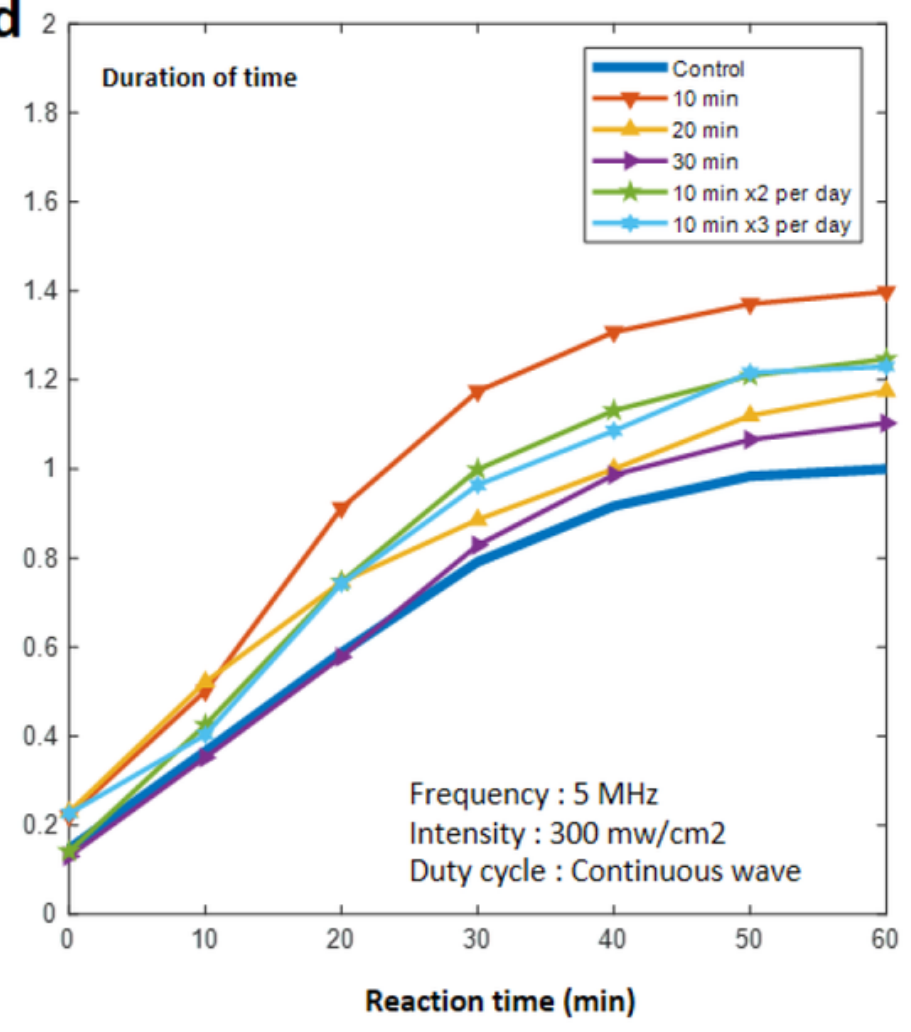

Figure 4

Proliferation rates of hAdMSCs depending on various parameters based on BrdU incorporation assay. (a) Frequency $(4,5,6,9,10 \mathrm{MHz})$ dependence. (b) Intensity $(100,300,500,700,900 \mathrm{~mW} / \mathrm{cm} 2)$ dependence. (c) Duty cycle $(20,40,60,80,100 \%)$ dependence. (d) Duration of time $(10,20,30,10 \times 2,10 \times 3$ min per day) dependence. hAdMSCs: Human adipose derived mesenchymal stem cells; BrdU: Bromodeoxyuridine. 


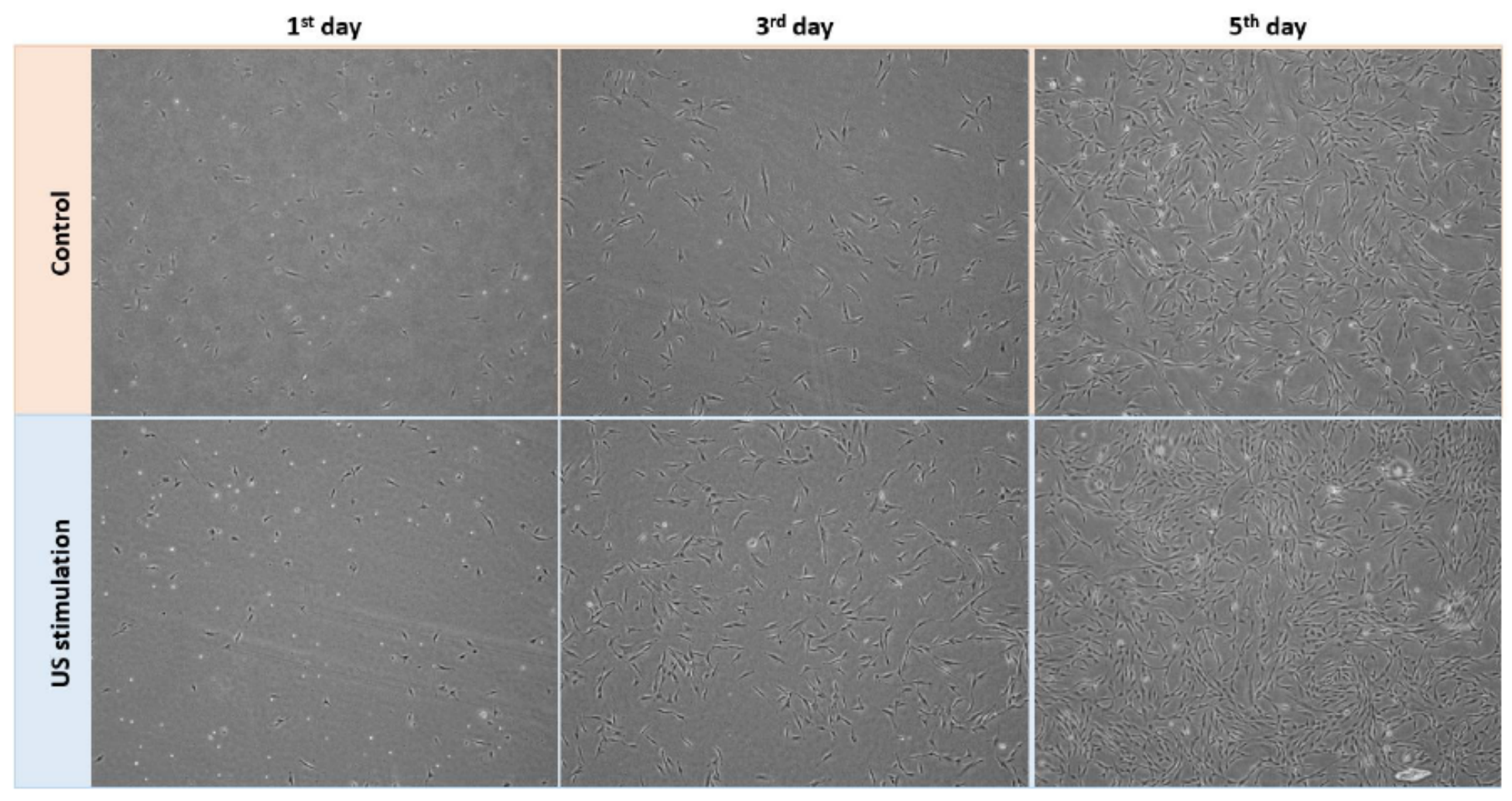

\section{Figure 5}

Images of the control and the stimulated group at passage 2. The seeding density was $2170 \mathrm{cell} / \mathrm{s} / \mathrm{cm} 2$. There was no difference in cell proliferation rate on the first day. However, on the third and fifth days, the proliferation rate of cells stimulated with LIUS was higher than that in the control group. LIUS: Lowintensity ultrasound.
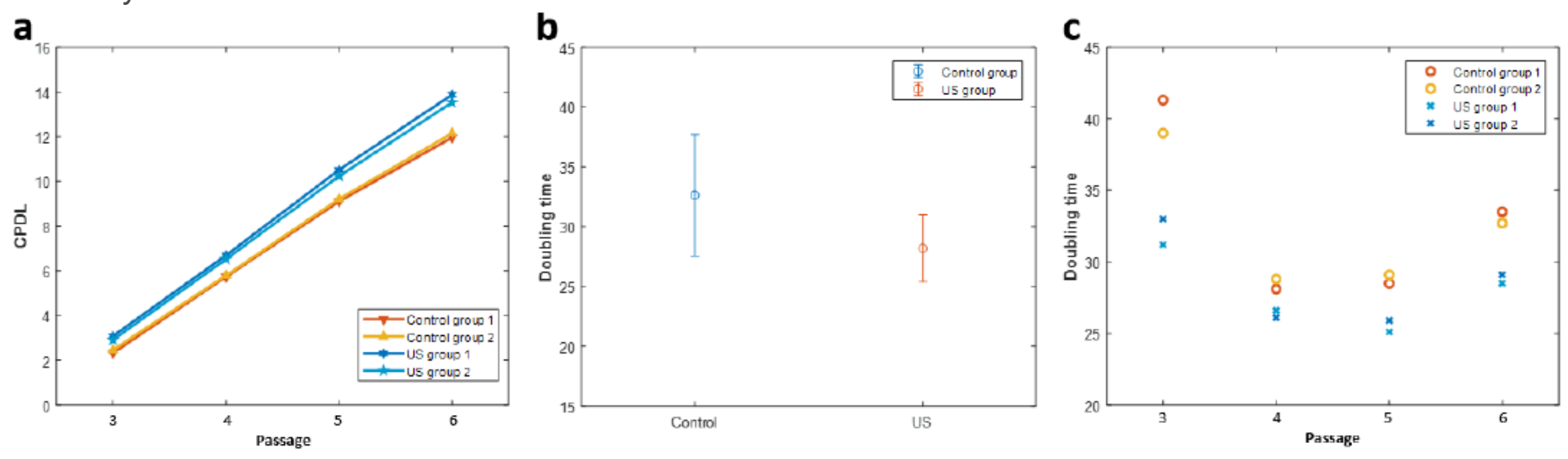

\section{Figure 6}

Graphical analysis of CPDL of control and LIUS stimulation groups. (a) CPDLs of control and stimulated groups from passages 3 to 6 . (b) Average doubling time of control and stimulated groups from passages 3 to 6. (c) Change of doubling time from passage 3 to passages 4, 5, and 6. CPDL: Cumulative population doubling level; LIUS: Low-intensity ultrasound. 